\title{
Self Efficacy and Spirituality - is there a correlation
}

\author{
Aashni Cheda ${ }^{1}$, Tehreem Hanware ${ }^{2}$, Nidhi Shah ${ }^{3}$, Neha Dalal ${ }^{4}$ \\ ${ }^{1-3}$ TYBA students ${ }^{4}$ Assistant professor \\ Department of Psychology, L.S Raheja College of Arts and Commerce, Mumbai. \\ Corresponding author: Ms. Neha Dalal \\ Email-neha.dalal@1sraheja.org
}

\begin{abstract}
Background: Spirituality has been prevalent since the evolution of mankind started. However, the means of practicing spirituality has changed over time. It is claimed by many that any form of spirituality has a positive profound effect on the individuals in various aspects. This research is based on the role played by spirituality on self efficacy, which is people's beliefs about their capabilities to produce results.

Methods: Through method of convenient and purposive sampling, 40 participants both male and female were administered with the General Self Efficacy. They were classified as being spiritual or atheist by self report method. Whereby, atheist declared non belief in higher power, and spiritual participants reported belief in higher power. An exact mode of practicing spirituality was not considered. Groups of spiritual individuals and atheists were considered equally in terms of the number of males and females. They were given the General Self-Efficacy Scale.

Results: The result was not significant, which is there is no significant difference between spiritual individuals and atheists in terms of self efficacy.

Conclusion: Spiritual individuals and atheists do not differ in self efficacy while many factors may remain that determine this relationship
\end{abstract}

Keywords: spiritual, spirituality, atheists, self efficacy

(Paper received $-5^{\text {th }}$ January 2018, Peer review completed $-13^{\text {th }}$ January 2018)

(Accepted $-16^{\text {th }}$ January 2018)

\section{INTRODUCTION}

\section{Spirituality and Self Efficacy}

Spirituality is more personal than religion in that it is something people define for themselves that is largely free of rules, regulations and responsibilities typical of religions. Therefore, people may be spiritual but not religious. Spirituality is a very personal matter which something people feel different about. Spirituality is to do with deep feelings and beliefs both religious and non religious and often involves questions about our identity, existence and the purpose of life. Good spiritual health is known to bring with it a sense of inner peace and comfort and it is a process of personal transformation [1].

People tend to follow others such as their friends, parents, saints etc. and get inspired by them in spiritual practices as a way of progressing on the path of self fulfilment, happiness and enlightenment. Spiritual practices help build experience and increase our self awareness so that they're more conscious of their awareness and have a more robust being. The source of spirituality is the faith on the unseen and omnipresent action of the divine. Deep within the soul, the sense of a useable force's constant nurturing helps increase self efficacy [2].

Atheism, though a much modern term can be explained in the widest sense as the absence in the belief of the existence of any power above what you pave for yourself. Atheism is also the rejection of belief in the 
existence of God. Atheism also has a scientific outlook, since humans live in a scientific world where matters exist solely with the help of observability, the existence of a deity cannot be observed. Also, one cannot be too sure of its existence due to the unavailability of tangible proof [3].

Albert Bandura speaks of perceived self-efficacy, which is defined as people's beliefs about their capabilities to produce designated levels of performance that exercise influence over events that affect their lives. Selfefficacy beliefs determine how people feel, think, motivate themselves and behave. Such beliefs produce these diverse effects through four major processes. They include cognitive, motivational, affective and selection processes [4].

A strong sense of efficacy enhances human accomplishment and personal well-being in many ways. People with high assurance in their capabilities approach difficult tasks as challenges to be mastered rather than as threats to be avoided. Such an efficacious outlook fosters intrinsic interest and deep engrossment in activities. They set themselves challenging goals and maintain strong commitment to them. They heighten and sustain their efforts in the face of failure. They quickly recover their sense of efficacy after failures or setbacks. They attribute failure to insufficient effort or deficient knowledge and skills which are acquirable. They approach threatening situations with assurance that they can exercise control over them. Such an efficacious outlook produces personal accomplishments, reduces stress and lowers vulnerability to depression [5].

Self efficacy is related to many dimensions in life. Self efficacy helps in overall development, it helps in academics, students who are have higher self efficacy utilize higher propensity, venture and strength in performing tasks that are academic and feel secure of their abilities, thus self efficacy can influence their overall academic achievement. Self efficacy promotes motivation at workplace. Employees that are confident at their workplaces are always open to more challenges and newer, much harder assignments. They recover from failure much faster than those who score lower on the scales of self efficacy. Those who have scored low find it hard to believe in themselves and their abilities; also, they are not open to venture in unknown lands and are not ready to take risks in life. Self efficacy also plays a part in affective disorders. Children who score low on self efficacy are more susceptible to neuroticism, depression symptoms and anxiety disorder symptoms [6].

\section{Statement of Problem}

Spirituality in India has been a way of life since the early ages. India is a diverse culture a home to many religions and their practices, practices that aim to reach spiritual enlightenment and to build a complete sense of self. Spiritual books like the Bhagavad Gita, Bible, Quran, are known to provide answers to all of mankind's problems, a form of self efficacy. Religious books help provide a different, more efficient way of dealing with problems. Our spiritual practice inevitably produces positive results even at the outset. Perhaps one feels more relaxed after a sitting meditation or more at peace after a prayer, or more centred when one practices presence. As we continue on the path, these and other experiences deepen and prove that one can in fact practice effectively. Confidence grows (www.innerfrontier.org). Since India is such a vast land practicing so many religions the researcher wanted to know if these practices do genuinely help increase a person's self confidence and self efficacy. In modern days, atheism is at rise with the younger generation not believing in a power above them. So spirituality can sometimes aid in increasing self efficacy however, this does not imply that atheists lack self confidence and self efficacy. A lot of studies have stated that spiritual and self efficacy play a positive role in motivation, redeployment of soldier troops, and strategies used by teachers in class.

However, researcher could not find any definitive study on relationship between spirituality and self efficacy. Also not many studies are available on the people who do not follow any spiritual path or are atheist. The purpose of this study therefore was to investigate whether spirituality plays an important role in self efficacy, as against atheism.

Self efficacy: A person's belief in his or her ability or competency to perform a given task, reaches a goal, or overcome an obstacle.

Spirituality: According to Kees Waaijman the traditional meaning of spirituality is a process of reformation which "aims to recover the original shape of man, the image of God. To accomplish this, the reformation is oriented at a mould, which represents the original shape: in Judaism the Torah, in 
Christianity there is Christ, for Buddhism, Buddha, and in Islam, Muhammad. According to Christina Puchalski, Spirituality is the aspect of humanity that refers to the way individuals seek and express meaning and purpose and the way they experience the connectedness to the moment, to self,to others, to nature, and to the significant or scared.

Atheism: disbelief or lack of belief in the existence of God or gods. Baron d'Holbach said that "All children are born Atheists; they have no idea of God". Atheism is not a disbelief in God's or a denial of gods; it is a lack of beliefs in God.

A research conducted studied the self efficacy and spirituality among teachers in 2 schools. The scale consisted of three constructs, student engagement, instruction strategies and classroom management. The study revealed that belief had a direct effect on student engagement and an indirect effect on instructional strategies and classroom management [7]. Although it did not possess any direct relation on teacher self efficacy, the construct was related to belief regarding life.

A study conducted by Jose Luis Daniel in the US and Mexico studied the effects of workplace spirituality and stress. Their purpose was to study the relationship between the three dimensions of workplace spirituality which is inner life, meaningful work and sense of community. The results were found to be insignificant for sense of community and inner life. However, meaningful work was found to be negatively and significantly correlated with work stress for both countries. It was seen that in both countries when employees indulged in meaningful activities they perceived less stress. This study can be practically implicated by human resources managers and business specialist to understand to understand the importance of conducting meaningful activities at work to manage, control and prevent stress at work [8]. Research on spirituality, addiction and recovery has shown some consistent findings. Individuals with higher level of religiosity and spirituality are less likely to consume alcohol and drugs or consume very little when they do use them. Miller also confirmed that people who have lower levels of spirituality have an increased risk for substance abuse [9].

\section{METHODOLOGY}

\section{Design}

It was a simple observational study to find out the difference between the level of self efficacy among atheists and spirituality oriented individuals.

\section{Independent Variable}

2 levels of independent variable

1. Practice of Spirituality

2. Atheism

\section{Operational definition}

Spirituality -

- Visiting places of worship

- Meditating

- Following a particular sect or guru

Atheism

- Not believing in god

- Not visiting any place of worship

Dependent Variable

Scores on the scale of self efficacy

\section{Hypothesis}

Self efficacy is higher in people who practice spirituality than people who are atheist.

\section{Sampling}

A convenient sampling was used for the gathering of the data.

The researchers have taken into consideration age groups ranging from 18-60. The researchers have also considered the genders, both male and female. 


\section{Tools}

\section{General Self Efficacy Scale}

The researchers have used a Likert type rating scale ranging from 'Not at all true' to 'exactly true'. Scoring will go up in tools used

\begin{tabular}{|l|l|l|l|l|}
\hline & Not at all true & Hardly true & Moderately true & Exactly true \\
\hline All questions & 1 & 2 & 3 & 4 \\
\hline
\end{tabular}

The total score is calculated by finding the sum of all items. For the General Self Efficacy Scale the total score ranges between 10 and 40 with the higher score indicating more self efficacy. Internal reliability for General Self Efficacy Scale is equal to Cronbach's alphas between 0.76 and 0.90 . The General Self Efficacy Scale is correlated to emotion, optimism, work satisfaction. Negative coefficients were found for depression, stress, health complaints, burnout and anxiety [10].

\section{StatisticalTest}

The Mann-Whitney $\mathrm{U}$ is a non-parametric test used to assess for significant differences in a scale or ordinal dependent variable by a single dichotomous independent variable. It is the non-parametric equivalent of the independent samples t-test. This means that the test does not assume any properties regarding the distribution of the dependent variable in the analysis. This test was used to calculate the results of the significance of the difference in the levels of self-efficacy between individuals practicing spirituality and atheists. A non parametric test was used to calculate the statistic as the data was non linear.

\section{RESULTS}

The mean rank scores of the two groups on the self efficacy scale was 20.7 for the spiritual group and 20.3 for the atheist group. The $\mathrm{U}$ value was 195.5 and $\mathrm{Z}$ score was 0.11 which not significant. The statistic was non significant with $\mathrm{p}=0.4$

\section{DISCUSSION}

There was no significant difference between the levels of self efficacy among spiritual individuals and atheists; therefore, the null hypothesis was accepted and the alternative directional hypothesis was rejected. The researchers found the results to be not significant with the help of Mann Whitney U test. Sample A consisted of spiritual individuals both male and female whereas, Sample B consisted of Atheists both male and female. Each sample consisted of 10 male and 10 female combined. It is expected that, spiritually oriented people are able to use both - emotion-focused coping technique and problem focused coping technique. The former because they are accepting towards things beyond their control and it can provide something positive upon which to focus, thereby helping elicit a relaxation response. The latter because they believe that their life has a larger purpose which can be helpful during stressful times, hence, a high level of self efficacy is prevalent among them.

On the other hand, atheists do not believe in a higher force outside them because of which they can carry out an activity without being dependent on anything beyond themselves and hence the likelihood of them performing the activity to the optimal level is higher. This also results in a high self efficacy. This was not the case because the sample size in this study was very small as compared to what would be the ideal size. Other variables such as parenting style, problem solving techniques, etc can have a higher impact on self efficacy. There are 4 sources of self efficacy given by Bandura. In a study on the sources of self efficacy on students, the following was observed

Past performance: Past performance is one of the greatest contributors to students' confidence. If students have been successful at a particular skill in the past, they will probably believe that they will be successful at the skill in the future. 
Vicarious Experiences: When a student sees another student accomplish a task, the vicarious experience of observing a model can also have a strong influence on self-efficacy. By observing others like themselves perform tasks; individuals make judgments about their own capabilities.

Verbal Persuasion: Verbal persuasion such as telling the students "You can do this" can be important, however, it does not contribute as much as an individual's own experiences or vicarious experiences. The short-term effects of persuasion need to be coupled with actual successes.

Physiological Cues: The final source upon which self-efficacy beliefs are based are physiological cues. Sweaty hands or a dry mouth are often interpreted as signs of nervousness. Students may feel that such signs indicate they are not capable of succeeding at a particular task. Conversely, students may be aware of feeling relaxed before confronting a new situation and develop a higher sense of efficacy toward the task they face. Physiological cues are the weakest influence of the four presented here.

It was also seen that most atheists belonged in the age group of 18-30; the study can then say that atheism is more prevalent in the younger generation than in the older. Due to independence of having their own opinion without being influenced by their parents and others who don't share the same ideologies as them. Taking a look at the data received, it was seen that most atheist belonged in the age group of 18-30.

Of the total data collected by the researchers it was seen that atheism was more prevalent in men than in women. And more women practice spirituality than men. The reason for this could be the kind of the upbringing women in general receive in our society. They are not motivated to have their own opinion and point of view regarding sensitive topics such as religiosity.

The researchers measured the subjects on only one dimension which is self-efficacy. Other dimensions could also have been considered such as stress, academics, perception, performance, motivation etc. Along with self efficacy scale, the researchers could have used the Perceived Stress Scale by Sheldon Cohen and Marital Satisfaction Scale by Enrich. If the subjects were measured on more than one dimension, the results would have been more accurate and in depth. The researchers could have used a Daily Spiritual Experience Scale by DR. Underwood to measure the levels of spirituality and compare it to the levels of self efficacy to find out the correlation between them.

\section{REFERENCES}

1. Fife JE, Bond S, Byars-Winston A. Correlates and predictors of academic self efficacy among African American students. Education 2011;132(1):141-9.

2. Duffy RD, Lent RW. Relation of religious support to career decision self-efficacy in college students. J Career Assess 2008;16(3):360-9.

3. Duffy RD, Blustein DL. The relationship between spirituality, religiousness, and career adaptability. J Vocat Behav 2005;67(3):429-40.

4. Beattie T. The New Atheists: The Twilight of Reason and the War on Religion. Orbis Books; 2007.

5. Asghari F, Saadat S, Atefi Karajvandani S, Janalizadeh Kokaneh S. The Relationship between Academic Self-Efficacy and Psychological Well-Being, Family Cohesion, and Spiritual Health among Students of Kharazmi University. Iranian J Med Educn 2014;14(7):581-93.

6. Bandura A. Self-efficacy: The exercise of control. Macmillan; 1997.

7. Schwarzer R. Self-efficacy: Thought control of action. Taylor \& Francis; 2014.

8. Bandura A, editor. Self-efficacy in changing societies. Cambridge university press; 1995.

9. Cashwell CS, Young J. Integrating spirituality and religion into counseling: A guide to competent practice. American Counseling Association; 2005.

10. Sherer M, Maddux JE, Mercandante B, Prentice-Dunn S, Jacobs B, Rogers RW. The self-efficacy scale: Construction and validation. Psychol Rep 1982;51(2):663-71.

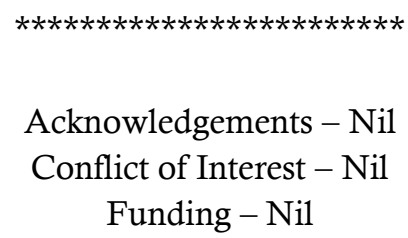

